\title{
Effects of Drinking Water Temperature and Flow Rate during Cold Season on Growth Performance, Nutrient Digestibility and Cecum Microflora of Weaned Piglets
}

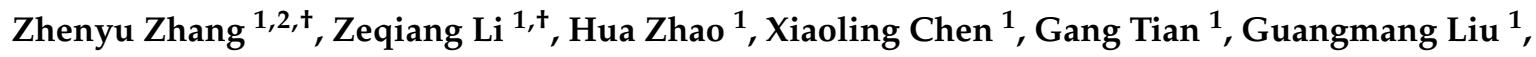 \\ Jingyi Cai ${ }^{1}$ and Gang Jia ${ }^{1, *}$ \\ 1 Animal Nutrition Institute, Sichuan Agricultural University, Chengdu 611130, Sichuan, China; \\ zhangzheny1111@126.com (Z.Z.); lizeqiang896527762@126.com (Z.L.); zhua666@sicau.edu.cn (H.Z.); \\ xlchen@sicau.edu.cn (X.C.); 13555@sicau.edu.cn (G.T.); liugm@sicau.edu.cn (G.L.); 11890@sicau.edu.cn (J.C.) \\ 2 Institute of Animal Husbandry and Veterinary Medicine, Meishan Vocational Technical College, \\ Meishan 620010, Sichuan, China \\ * Correspondence: 11988@sicau.edu.cn; Tel.: +86-028-8629-0922 \\ + These authors contributed equally to this work.
}

Received: 9 May 2020; Accepted: 15 June 2020; Published: 18 June 2020

check for updates

Simple Summary: Water is an essential nutrient pigs need to sustain life and ensure growth. Determining the appropriate drinking water supply parameters during cold weather are critical for the welfare and growth of pigs, especially vulnerable weaned piglets. This study explored different combinations of drinking water temperature (DWT) and flow rate (DWF) for weaned piglets during winter. It measured their growth performance, nutrient digestibility and cecum microbial diversity, aiming to figure out the optimal water supplying conditions for weaned piglets. The results indicated that a combination of DWT of $30^{\circ} \mathrm{C}$ and DWF of $300 \mathrm{~mL} / \mathrm{min}$ decreased diarrhea occurrence. Furthermore, this increased growth performance and nutrient digestibility, accompanied by improvement of the dominant cecum microflora, mainly manifested in a reduced abundance of Proteobacteria and increased abundance of Bacteroidetes. This study enriches our understanding of the connection between water supply, growth performance and cecum microbiota on weaned piglets during the cold season.

Abstract: Although water is one of the most important nutrients and is essential for various
physiological processes within the body, it does not receive adequate consideration when ensuring
optimal nutrition and growth performance in piglets. This study was conducted to investigate
the effects of drinking water temperature (DWT) and flow rate (DWF) on growth performance,
nutrient digestibility and cecum microflora in weaned piglets during cold weather. Sixty-four piglets
with an average body weight of $8.60 \pm 0.5 \mathrm{~kg}$ were allotted into four groups with four replicates
in each group and four pigs in each replicate. The DWT and DWF were set for each group as follows:
$(1) 13{ }^{\circ} \mathrm{C}+300 \mathrm{~mL} / \mathrm{min},(2) 13^{\circ} \mathrm{C}+700 \mathrm{~mL} / \mathrm{min}$, (3) $30^{\circ} \mathrm{C}+300 \mathrm{~mL} /$ min and $(4) 30^{\circ} \mathrm{C}+700 \mathrm{~mL} / \mathrm{min}$,
respectively. All groups were fed the same diet during the $28 \mathrm{~d}$ trial. The body weight at day 0 and day
29 , as well as daily feed intake, were recorded. Diarrhea severity was assessed every day. Fresh fecal
samples were collected for four consecutive days at the end of the experiment for the digestibility test.
Cecum content was collected after sacrifice for microbial composition analysis. The results indicated
that: (1) DWT at $30{ }^{\circ} \mathrm{C}$ promoted the average daily gain (ADG) of weaned piglets considerably
$(p=0.043)$ and decreased feed to weight ratio when compared with DWT at $13{ }^{\circ} \mathrm{C}(p=0.045)$.
DWF had no substantial effect on the growth performance of piglets ( $p>0.05$ ). (2) The $30{ }^{\circ} \mathrm{C}$ DWT
groups had higher apparent digestibility of crude protein, crude fat and energy than the $13{ }^{\circ} \mathrm{C}$ DWT
groups $(p<0.05)$, while DWF had no significant effect on the apparent digestibility of nutrients
$(p>0.05)$. (3) DWT at $30^{\circ} \mathrm{C}$ increased the Bacteroidetes abundance and decreased the Proteobacteria
abundance in cecum digesta. The change in these two factors may be related to a decrease in diarrhea 
and the improvement of growth performance. Different DWF had no substantial effect on the cecum microbial structure. To sum up, providing a DWT of $30^{\circ} \mathrm{C}$ to weaned piglets in cold weather reduced the abundance of harmful bacteria in the cecum and improved the apparent nutrient digestibility, which is beneficial for maintaining a healthy intestinal microenvironment and promoting growth performance. A lower DWF of $300 \mathrm{~mL} / \mathrm{min}$ had no adverse effect on growth performance. Therefore, a combination of $30^{\circ} \mathrm{C}+300 \mathrm{~mL} / \mathrm{min}$ is recommended for weaned piglets during cold weather for the consideration of animal welfare and production efficiency.

Keywords: water parameters; winter; pigs; growth performance; nutrient utilization; microflora

\section{Introduction}

Water is necessary for several physiological activities and plays a crucial role in regulating body temperature, promoting digestive tract development and maintaining the health of the urinary system [1]. Although water is the nutrient most consumed by animals, little research has been carried out to explore the appropriate supply parameters, such as drinking water temperature (DWT) and flow rate (DWF), for weaned animals. Inappropriate DWT and DWF may have an adverse effect on them. After weaning, the water source of young animals is switched from warm, slowly flowing breast milk to room temperature, fast-flowing tap water, which can cause stress during the cold season. Cold water stress, together with feed transition, environmental stress and social stress, can affect the gastrointestinal tract health of young animals, leading to poor digestibility and growth performance [2].

Gastrointestinal tract health is known to be largely affected by the composition of intestinal microflora [3]. The intestinal microflora is a complex system and it is increasingly being accepted as a factor that shapes host metabolism and health [4]. Recent studies have found that the intestinal microflora in pigs play a crucial role in nutrient processing and energy harvesting [5,6], which, in turn, leads to variation in feed efficiency.

In these contexts, improving current knowledge of how DWT and DWF can impact the intestinal digestion and microflora profile could be of high relevance for the welfare of weaned animals. Thus, this study provided different combinations of DWT and DWF to weaned piglets during the cold season, and measured the growth performance, nutrient digestibility and cecum microbial diversity, aiming to figure out the appropriate DWT and DWF for weaned piglets and enhance the understanding of their association with intestinal microflora.

\section{Materials and Methods}

All of the experimental procedures that were used in this research were in accordance with the ARRIVE guidelines and the Regulation on the Administration of Laboratory Animals (2017, China State Council). The Institutional Animal Care and Use Committee of Sichuan Agricultural University approved these procedures (SCAUAC201711-2).

\subsection{Animals and Experimental Design}

Sixty-four 30-d-old DLY (Duroc $\times$ Landrace $\times$ Yorkshire $)$ weaned piglets $(8.6 \pm 0.5 \mathrm{~kg}$, mean \pm SD) were randomly divided into four groups with four replicates in each group and four pigs in each replicate, in a balanced sex ratio ( 2 males and 2 females). Each replicate was kept in an individual pen $(2.5 \mathrm{~m} \times 3 \mathrm{~m})$ under temperature-controlled conditions $\left(22-25^{\circ} \mathrm{C}\right)$ with a $12 \mathrm{~h}: 12 \mathrm{~h}$ light-dark cycle for 28 days. Different DWT and DWF were provided for each group: (1) $13{ }^{\circ} \mathrm{C}+300 \mathrm{~mL} / \mathrm{min}$, (2) $13{ }^{\circ} \mathrm{C}+700 \mathrm{~mL} / \mathrm{min}$, (3) $30{ }^{\circ} \mathrm{C}+300 \mathrm{~mL} / \mathrm{min}$ and (4) $30{ }^{\circ} \mathrm{C}+700 \mathrm{~mL} / \mathrm{min}$, respectively. All groups were fed the same diet for starting pigs according to the nutritional requirements recommended by NRC [7]. Each pen contained two pig waterers $(6.8 \mathrm{~cm} \times 2 \mathrm{~cm}$. stainless steel, Model WB20XH, 
Zhenhaidongyi Machinery co. LTD, Ningbo, China). The piglets were provided with free access to feed and drinking water.

\subsection{Feeding and Diarrhea Occurrence}

At the start and end of the experiment, pigs were weighed in each pen as a unit. Feed consumption was recorded daily. The average daily feed intake (ADFI), average daily gain (ADG) and feed-to-gain ratio (F:G) were calculated. The feces of all pigs were scored every day, and the diarrhea severity was accessed according to Marquardt et al. [8]. The pigs with diarrhea were identified to avoid double counts. Diarrhea rate was calculated by dividing the number of pigs with diarrhea by the total number of pigs in each treatment. The diarrhea index was calculated as ( $\sum$ fecal scores for the duration of study)/ $n$ [9].

\subsection{Sample Collection}

Samples of the pelleted feed were taken after its production and stored at $-20{ }^{\circ} \mathrm{C}$ for later digestibility determination.

At day 25-28, fresh fecal samples were collected from 4 different locations in each pen floor and mixed in a sterile plastic bag. Ten milliliters of $10 \%$ hydrochloric acid was added to $100 \mathrm{~g}$ of feces to prevent the ammonia nitrogen evaporation. The mixture was then kept at $-20{ }^{\circ} \mathrm{C}$ for the digestibility test.

On day 29, one pig closest to the average pen weight was chosen from each replicate (sixteen pigs in total). The pigs were anesthetized by a combination of azaperone $(2 \mathrm{mg} / \mathrm{kg}$ body weight) and ketamine ( $25 \mathrm{mg} / \mathrm{kg}$ body weight) administered intramuscularly. Then the abdominal cavity was quickly opened. After all the intestinal segments were separated, $0.5 \mathrm{~g}$ cecum content of each piglet was collected and put in sterile EP tubes. The samples were stored at $-80^{\circ} \mathrm{C}$ for DNA extraction.

\subsection{Apparent Digestibility of Nutrients}

Acid-insoluble ash (AIA) was used as an inert marker to determine the apparent digestibility [10]. Samples were air-dried at $65{ }^{\circ} \mathrm{C}$ to a constant weight and crushed through a 40-mesh sieve. Then they were analyzed for crude protein (CP), crude ash and ether extract (EE) according to the following procedures from the Association of Official Analytical Chemists [11]: CP (Method 990.03), ash (Method 942.05) and EE (Method 920.39). The gross energy (GE) was measured in an automatic oxygen bomb calorimeter (PARR 6400; PARR Instruments CO., Moline, IL, US). The apparent nutrient digestibility was calculated according to Bovera et al. [12].

\subsection{Microflora Analysis}

A total of $0.3 \mathrm{~g}$ cecum digesta was thawed and employed to extract genomic DNA using the QIAamp DNA Stool Mini Kit (Qiagen, Valencia, USA) following the manufacturer's instructions. The integrity and quantification of DNA were determined by agarose gel electrophoresis and a NanoDrop ND-2000 spectrophotometer (Thermo Fisher, USA), respectively. The universal primer sequence, 515F (5'-GTGYCAGCMGCCGCGGTAA-3') and 806R (5'-GGACTACHVGGGTWTCTAAT-3'), were used to amplify the $\mathrm{V} 4$ region of the $16 \mathrm{~S}$ rDNA gene. PCR was performed with the following amplification conditions: $95{ }^{\circ} \mathrm{C}$ for $2 \mathrm{~min}$; 25 cycles at $95{ }^{\circ} \mathrm{C}$ for $1 \mathrm{~min}, 55^{\circ} \mathrm{C}$ for $1 \mathrm{~min}, 72{ }^{\circ} \mathrm{C}$ for $1 \mathrm{~min}$ and $72{ }^{\circ} \mathrm{C}$ for $5 \mathrm{~min}$. The sequence readings were processed on the QIIME v1.9.1 pipe [13] using the default settings. Readings were clustered into operational taxonomic units (OTUs) with $97 \%$ sequence similarity and picked by the subsampling open reference approach at $10 \%$ of sequences subsampled. Representative sequences were assigned to a classification of bacteria 16S GreenGenes v.13.8 reference database [14] according to the $90 \%$ confidence threshold, and sequence alignment was obtained through uclust. Chimera Slayer was employed to remove the chimeric sequence, and singletons and OTUs with a relative abundance of less than $0.005 \%$ in all samples were removed, according to Bokulich et al. [15]. The Vegan R package was used to calculate the alpha-diversity 
indexes, including Chao I, Simpson, Shannon and phylogenetic diversity (PD) whole tree. Principal component analysis was used to reduce the dimensions of the cecum microflora data.

\subsection{Statistical Analysis}

The statistical calculations were analyzed using the SPSS software package (SPSS vs. 24, SPSS Inc., Chicago, IL, USA). The statistical difference of normally distributed data, including growth performance, diarrhea rate and nutrient digestibility, were analyzed by using two-way ANOVA. The relative abundance of microbial phyla, genera and OTUs were determined using the nonparametric Kruskal-Wallis test. All $p$-values of the bacterial community obtained by the nonparametric Kruskal-Wallis test were corrected for the false discovery rate. A value of $p<0.05$ was considered significant.

These sequence data were submitted to the NCBI database under accession number PRJNA630063.

\section{Results}

As no significant interaction was detected in the parameters of Tables 1-4, results will be described by the main effects.

Table 1. Effects of drinking water temperature and flow rate on the growth performance of weaned piglets ${ }^{1}$.

\begin{tabular}{|c|c|c|c|c|c|c|c|c|}
\hline \multirow{2}{*}{ Items } & \multirow{2}{*}{$\begin{array}{l}\text { DWT } \\
\text { DWF }\end{array}$} & \multicolumn{2}{|c|}{$13^{\circ} \mathrm{C}$} & \multicolumn{2}{|c|}{$30^{\circ} \mathrm{C}$} & \multicolumn{3}{|c|}{$p$-Value } \\
\hline & & $300 \mathrm{~mL} / \mathrm{min}$ & $700 \mathrm{~mL} / \mathrm{min}$ & $300 \mathrm{~mL} / \mathrm{min}$ & $700 \mathrm{~mL} / \mathrm{min}$ & DWT & DWF & $\mathrm{DWT} \times \mathrm{DWF}$ \\
\hline Initial BW (kg) & & $8.60 \pm 0.14$ & $8.60 \pm 0.24$ & $8.60 \pm 0.18$ & $8.60 \pm 0.08$ & 1.000 & 1.000 & 1.000 \\
\hline Final BW (kg) & & $20.54 \pm 1.07$ & $18.95 \pm 1.57$ & $20.79 \pm 0.64$ & $21.04 \pm 1.12$ & 0.065 & 0.267 & 0.139 \\
\hline $\operatorname{ADG}(\mathrm{kg} / \mathrm{d})$ & & $0.43 \pm 0.04$ & $0.37 \pm 0.05$ & $0.44 \pm 0.02$ & $0.44 \pm 0.04$ & 0.043 & 0.220 & 0.103 \\
\hline ADFI $(\mathrm{kg} / \mathrm{d})$ & & $0.65 \pm 0.06$ & $0.63 \pm 0.03$ & $0.65 \pm 0.04$ & $0.66 \pm 0.06$ & 0.636 & 0.790 & 0.583 \\
\hline$F: G$ & & $1.53 \pm 0.05$ & $1.73 \pm 0.25$ & $1.49 \pm 0.04$ & $1.48 \pm 0.02$ & 0.045 & 0.168 & 0.124 \\
\hline
\end{tabular}

${ }^{1}$ Values are means \pm SEM $(n=4) ; \mathrm{DWT}=$ drinking water temperature; $\mathrm{DWF}=$ drinking water flow rate; $\mathrm{BW}=$ body weight; $A D G=$ average daily gain; $F: G=$ the ratio of feed to gain.

Table 2. Effects of drinking water temperature and flow rate on the diarrhea rate and index of weaned piglets ${ }^{1}$.

\begin{tabular}{|c|c|c|c|c|c|c|c|}
\hline \multirow{2}{*}{ Items } & \multicolumn{2}{|c|}{$13^{\circ} \mathrm{C}$} & \multicolumn{2}{|c|}{$30{ }^{\circ} \mathrm{C}$} & \multicolumn{3}{|c|}{$p$-Value } \\
\hline & $300 \mathrm{~mL} / \mathrm{min}$ & $700 \mathrm{~mL} / \mathrm{min}$ & $300 \mathrm{~mL} / \mathrm{min}$ & $700 \mathrm{~mL} / \mathrm{min}$ & DWT & DWF & $\mathrm{DWT} \times \mathrm{DWF}$ \\
\hline Diarrhea rate $(\%)$ & $16.07 \pm 2.31$ & $17.63 \pm 1.98$ & $7.59 \pm 4.28$ & $9.37 \pm 5.12$ & 0.001 & 0.380 & 0.953 \\
\hline Diarrhea index & $0.55 \pm 0.04$ & $0.63 \pm 0.06$ & $0.32 \pm 0.06$ & $0.41 \pm 0.08$ & 0.000 & 0.024 & 0.917 \\
\hline
\end{tabular}

${ }^{1}$ Values are means \pm SEM $(n=4) ; \mathrm{DWT}=$ drinking water temperature; DWF = drinking water flow rate.

Table 3. Effects of drinking water temperature and flow rate on the apparent nutrient digestibility ${ }^{1}$.

\begin{tabular}{|c|c|c|c|c|c|c|c|}
\hline \multirow{2}{*}{ Items } & \multicolumn{2}{|c|}{$13^{\circ} \mathrm{C}$} & \multicolumn{2}{|c|}{$30{ }^{\circ} \mathrm{C}$} & \multicolumn{3}{|c|}{$p$-Value } \\
\hline & $300 \mathrm{~mL} / \mathrm{min}$ & $700 \mathrm{~mL} / \mathrm{min}$ & $300 \mathrm{~mL} / \mathrm{min}$ & $700 \mathrm{~mL} / \mathrm{min}$ & DWT & DWF & $\mathrm{DWT} \times \mathrm{DWF}$ \\
\hline CP (\%) & $65.78 \pm 2.38$ & $67.21 \pm 3.02$ & $71.81 \pm 2.21$ & $72.96 \pm 1.30$ & 0.000 & 0.287 & 0.906 \\
\hline Ash (\%) & $48.05 \pm 3.22$ & $46.39 \pm 1.67$ & $48.85 \pm 3.17$ & $49.56 \pm 1.81$ & 0.266 & 0.785 & 0.499 \\
\hline EE $(\%)$ & $56.60 \pm 4.58$ & $52.13 \pm 3.22$ & $59.80 \pm 1.80$ & $58.42 \pm 5.44$ & 0.035 & 0.169 & 0.456 \\
\hline Energy (\%) & $74.89 \pm 2.30$ & $73.54 \pm 2.30$ & $77.44 \pm 0.98$ & $76.99 \pm 1.51$ & 0.007 & 0.354 & 0.640 \\
\hline
\end{tabular}

${ }^{1}$ Values are means \pm SEM $(n=4)$; DWT = drinking water temperature; DWF = drinking water flow rate; $\mathrm{CP}=$ crude protein; $\mathrm{EE}=$ ether extract. 
Table 4. Effects of drinking water temperature and flow rate on the alpha diversity of cecum microflora ${ }^{1}$.

\begin{tabular}{cccccccc}
\hline \multirow{2}{*}{ Items } & \multicolumn{2}{c}{$\mathbf{1 3}{ }^{\circ} \mathbf{C}$} & \multicolumn{2}{c}{$3 \mathbf{~}^{\circ} \mathbf{C}$} & \multicolumn{3}{c}{$p$-Value } \\
\cline { 2 - 7 } & $\mathbf{3 0 0} \mathbf{~ m L} / \mathbf{m i n}$ & $\mathbf{7 0 0} \mathbf{~ m L} / \mathbf{m i n}$ & $\mathbf{3 0 0} \mathbf{~ m L} / \mathbf{m i n}$ & $\mathbf{7 0 0 ~} \mathbf{~ L} / \mathbf{m i n}$ & DWT & DWF & DWT $\times$ DWF \\
\hline Chao ${ }^{1}$ & $885.12 \pm 185.78$ & $1212.21 \pm 239.51$ & $818.24 \pm 946.79$ & $946.79 \pm 218.81$ & 0.110 & 0.036 & 0.323 \\
Shannon & $4.13 \pm 0.50$ & $4.71 \pm 0.22$ & $4.19 \pm 0.58$ & $4.62 \pm 0.32$ & 0.960 & 0.035 & 0.715 \\
Simpson & $0.93 \pm 0.02$ & $0.97 \pm 0.01$ & $0.93 \pm 0.06$ & $0.96 \pm 0.01$ & 0.906 & 0.072 & 0.963 \\
PD & $48.76 \pm 11.34$ & $65.22 \pm 13.85$ & $43.47 \pm 3.69$ & $50.92 \pm 8.32$ & 0.075 & 0.035 & 0.387 \\
\hline
\end{tabular}

${ }^{1}$ Values are means \pm SEM $(n=4)$; DWT = drinking water temperature; DWF = drinking water flow rate.

\subsection{Growth Performance and Diarrhea Occurrence}

Data on the effects of DWT and DWF on growth performance are presented in Table 1. DWT at $30{ }^{\circ} \mathrm{C}$ showed a trend of increasing the final body weight (BW; $\left.p=0.065\right)$ and promoted the ADG of weaned piglets considerably $(p=0.043)$ compared to the $13{ }^{\circ} \mathrm{C}$ groups. Additionally, it reduced the F: $\mathrm{G}$ ratio $(p=0.045)$, but no substantial effect was detected on ADFI $(p=0.636)$.

Low DWT caused a high incidence of diarrhea (Table 2). The diarrhea rate and index of weaned piglets in the $13{ }^{\circ} \mathrm{C}$ groups were significantly higher than those in the $30{ }^{\circ} \mathrm{C}$ groups $(p=0.001$ and $p=0.000$, respectively). Compared with DWT at $13{ }^{\circ} \mathrm{C}$, DWT at $30^{\circ} \mathrm{C}$ reduced the diarrhea rate of weaned piglets approximately by $50.00 \%$ and the diarrhea index by $38.14 \%$. There was no substantial effect of DWF on the diarrhea rate $(p=0.380)$.

\subsection{Nutrient Digestibility}

The DWT at $30^{\circ} \mathrm{C}$ promoted the apparent digestibility of $\mathrm{CP}(p=0.000), \mathrm{EE}(p=0.035)$ and energy $(p=0.007)$, but had no substantial effect on the digestibility of crude ash $(p=0.266$; Table 3$)$. The DWF had no significant effect on the digestibility of $\mathrm{CP}, \mathrm{EE}$, crude ash or energy $(p>0.05)$.

\subsection{Sequencing, Richness and Diversity of the Bacterial Community}

The dilution curve gradually flattened with the increase of sequencing depth, indicating reasonable sequencing quantities (Figure 1). A total of 1377, 1762, 1052 and 1263 OTUs were obtained in the $13{ }^{\circ} \mathrm{C}+300 \mathrm{~mL} / \mathrm{min}, 13{ }^{\circ} \mathrm{C}+700 \mathrm{~mL} / \mathrm{min}, 30^{\circ} \mathrm{C}+300 \mathrm{~mL} / \mathrm{min}$ and $30^{\circ} \mathrm{C}+700 \mathrm{~mL} / \mathrm{min}$ group, respectively (Figure 2).

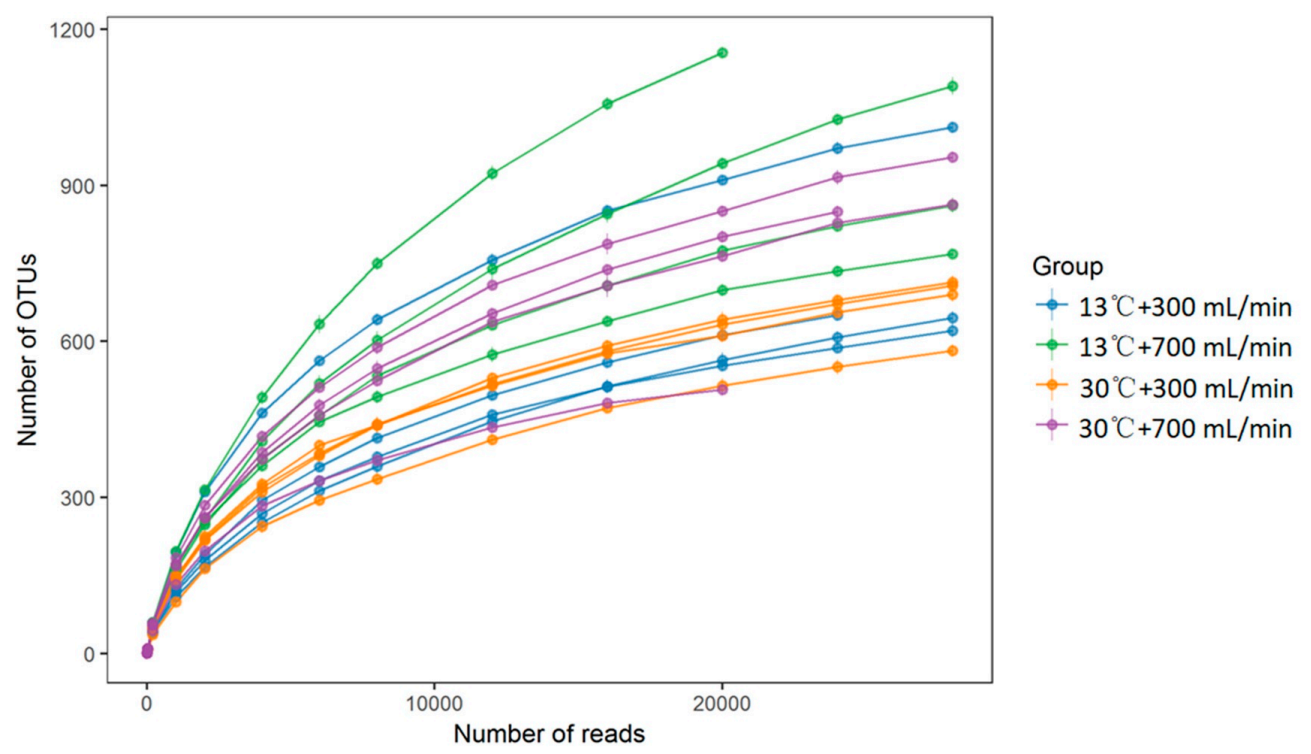

Figure 1. Rarefaction curves based on operational taxonomic units (OTUs) in the cecum digesta. 


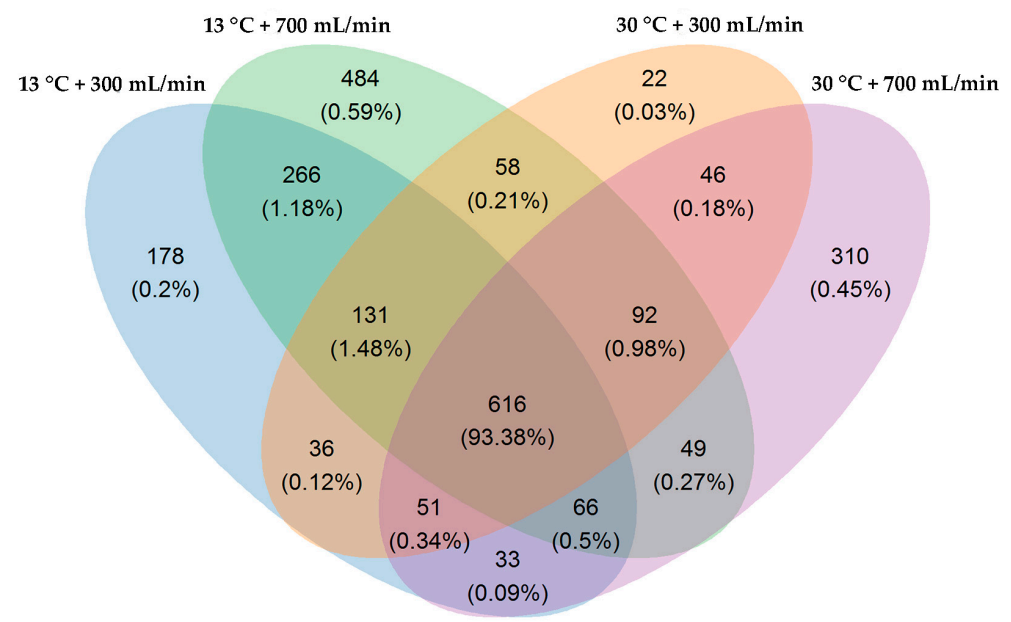

Figure 2. Venn diagrams of shared genes.

The indexes of Chao 1, Simpson, Shannon and Faith's PD, which all indicate species richness, were calculated in order to evaluate the alpha diversity in different ways (Table 4). The indexes of Chao1, Faith's PD and Shannon were not affected by DWT $(p>0.05)$, and were increased with the rise of DWF ( $p<0.05)$. The Simpson index was not affected by either DWT or DWF $(p>0.05)$. There was no substantial effect of DWT and DWF interaction on the alpha diversity index $(p>0.05)$.

The principal coordinate analysis showed that samples of the same treatment could be well clustered, indicating the results were meaningful (Figure 3). Different processing groups were scattered in far apart locations on the coordinate system. The distance between the $13{ }^{\circ} \mathrm{C}+300 \mathrm{~mL} / \mathrm{min}$ group and the $13{ }^{\circ} \mathrm{C}+700 \mathrm{~mL} / \mathrm{min}$ group was relatively close. Meanwhile, the distance between the $30{ }^{\circ} \mathrm{C}+300 \mathrm{~mL} / \mathrm{min}$ group and the $30{ }^{\circ} \mathrm{C}+700 \mathrm{~mL} / \mathrm{min}$ group was near, indicating there is a relatively high similarity of microbial structure within the same DWT treatments. In comparison, when the DWF was at $700 \mathrm{~mL} / \mathrm{min}$, the aggregation degree of samples under the same DWF treatments was low, indicating that the microbial structure within the group was significantly different.

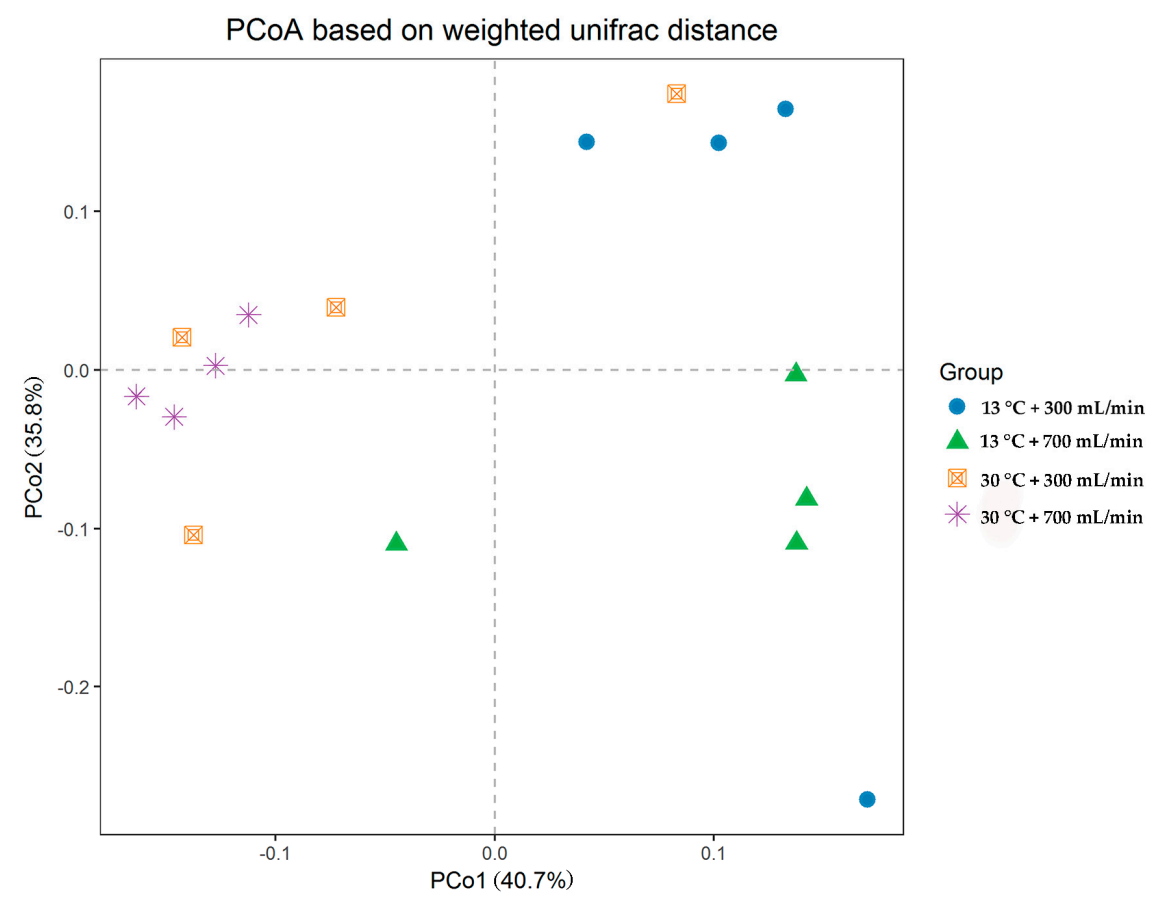

Figure 3. Principal co-ordinates analysis based on the weighted Unifrac metric of cecal microflora among all samples. 


\subsection{Microbiome Modulation at Taxonomic Levels}

Figure $4 \mathrm{~A}$ shows the top twelve bacterial phylum in the cecum digesta. Firmicutes constituted the most prevalent phylotype, comprising over $57.0 \%$ of the cecum microbial population, followed by Proteobacteria, Actinobacteria, Acidobacteria, Chloroflexi, Thaumarchaeota, Spirochaetae, Deferribacteres, Nitrospirae, Euryarchaeota and Verrucomicrobia. DWT at $30{ }^{\circ} \mathrm{C}$ increased the relative abundance of Bacteroidetes, and decreased the relative abundance of Proteobacteria, Actinobacteria, Acidobacteria, Chloroflexi and Thaumarchaeota $(p<0.05)$. DWF had no substantial effect on the relative abundance of microbes. There was no significant interaction between DWT and DWF on microbial phylotype $(p>0.05)$.

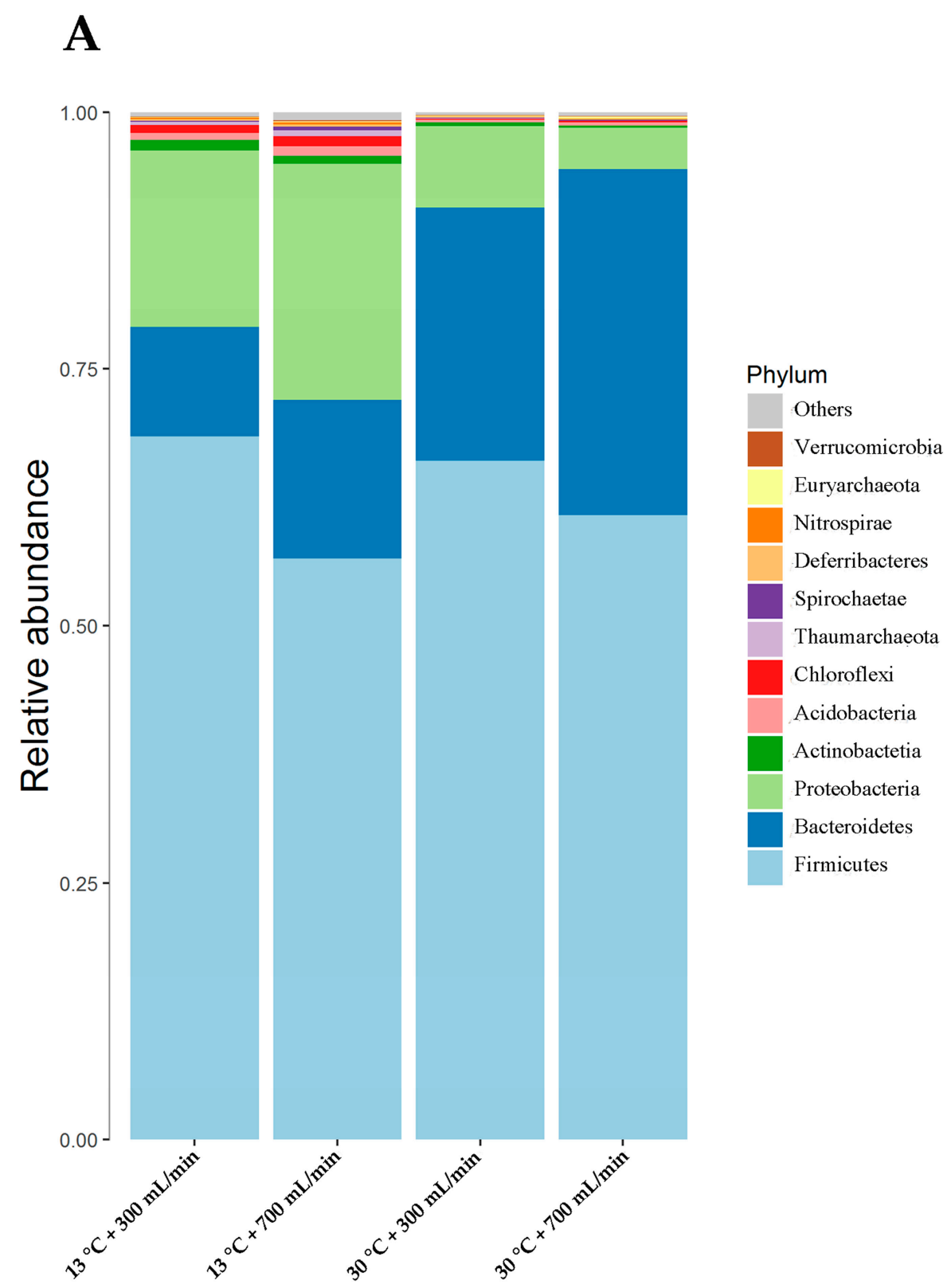

Figure 4. Cont. 


\section{B}
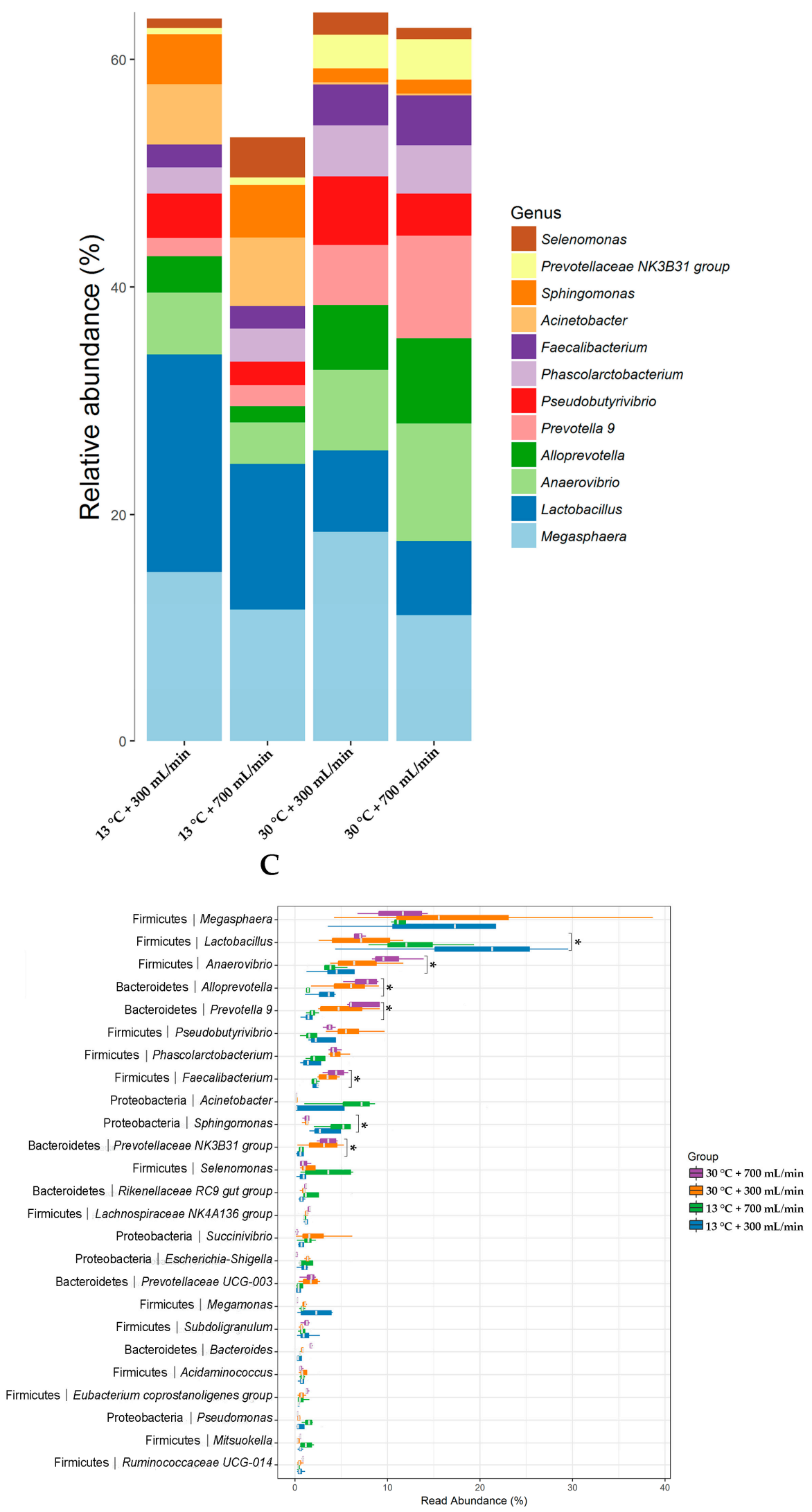

Figure 4. The relative abundance of the top twelve phyla (A) and genera (B) in the cecum digesta. (C) Boxplot at the genus level. * represents $p<0.05$. 
At the genus level, the prevalent phylotypes were Megasphaera, Lactobacillus, Anaerovibrio, Alloprevotella, Prevotella 9, Pseudobutyrivibrio, Phascolarctobacterium, Faecalibacterium, Acinetobacter, Sphingomonas, Prevotellaceae NK3B31 group and Selenomonas (Figure 4B,C). The DWT change had no substantial effect on the relative abundance of Megasphaera, Pseudobutyrivibrio, Phascolarctobacterium and Acinetobacter $(p>0.05)$. The DWT at $30{ }^{\circ} \mathrm{C}$ decreased the relative abundance of Lactobacillus and Sphingomonas, and improved the relative abundance of Anaerovibrio, Alloprevotella, Prevotella 9, Faecalibacterium and Prevotellaceae NK3B31 $(p<0.05)$. DWF had no significant effect on the relative abundance of microbes at the genus level $(p>0.05)$.

\section{Discussion}

After weaning, the water source of piglets changed from warm breast milk to cold tap water, which can easily cause diarrhea and reduce growth performance. When DWT is lower than the body temperature of pigs, extra energy is needed to warm up the incoming water. A previous study found that pigs provided with a DWT of $30{ }^{\circ} \mathrm{C}$ had a significantly higher growth performance compared with the ones provided with a DWT of $5{ }^{\circ} \mathrm{C}$ [16]. Similar results were obtained in the present study, with ADG increased by $10.00 \%$ and F:G decreased by $8.90 \%$ after DWT treatment at $30{ }^{\circ} \mathrm{C}$. Therefore, the piglets do not need to expend extra energy to heat up the water, and more energy can be used to increase their growth performance.

In addition to ambient temperature management, DWF was also important for the growth performance of piglets [17]. Nienber et al. [16] found that the effect of DWF was in close relation with the environmental temperature. At an ambient temperature of $35^{\circ} \mathrm{C}$, when the DWF was $100 \mathrm{~mL} / \mathrm{min}$ and $1100 \mathrm{~mL} / \mathrm{min}$, the average ADG of pigs was $0.278 \mathrm{~kg} / \mathrm{d}$ and $0.466 \mathrm{~kg} / \mathrm{d}$, respectively. While at an ambient temperature of $5{ }^{\circ} \mathrm{C}$, the average ADG of pigs decreased from 0.855 to $0.730 \mathrm{~kg} / \mathrm{d}$ under the same above mentioned DWF increase. These results suggest that the effect of DWT and DWF on livestock should be considered together. In the present study, no significant interaction was observed between DWT and DWF on the weaned piglet's growth performance, which may be due to different DWT and DWF conditions in these two studies.

Sudden changes in the environment and feed after weaning can stress piglets and increase diarrhea occurrence. The $13{ }^{\circ} \mathrm{C}$ groups had a higher diarrhea index than the $30^{\circ} \mathrm{C}$ groups, which may be due to the increased sympathetic nerve excitability and exacerbated bowel motility caused by drinking cold water [18,19].

The total bacterial community that inhabits the gastrointestinal tract of mammals numbers at about $10^{14}$, which consists of 500-1000 kinds of bacteria [20]. Under the combined action of these bacteria, the intestinal tract maintains a relatively stable microenvironment. Firmicutes and Bacteroidetes are the primary microflora in the intestine, accounting for more than $98 \%$ of all the bacteria, while the proportion of other phylum is only about $1 \%$ [21,22]. Healthy microflora plays a vital role in intestinal development, nutrient digestion absorption and immunity. Weaned piglets are susceptible to the influence of the external environment due to their immature physiological functions, resulting in the imbalance of intestinal flora and diarrhea. Bacteroidetes participate in carbohydrate fermentation, metabolism of polysaccharide, bile acid and steroid, and play an essential role in maintaining normal intestinal physiology and body health [23]. Grover et al. [24] found that the content of Bacteroidetes in the intestinal tracts of people with diarrhea was significantly lower than in the intestinal tracts of healthy ones. The present study showed that DWT at $13{ }^{\circ} \mathrm{C}$ reduced the relative abundance of Bacteroidetes, which may be one of the causes of diarrhea. Proteobacteria is a large group of bacteria, including many pathogenic members, such as Escherichia coli, Salmonella, Vibrio cholerae and Helicobacter pylori [25]. The relative abundance of Proteobacteria is known to be negatively related to the health status of its host. A small amount of Proteobacteria can coexist peacefully with the host, but as the number of Proteobacteria increases, it can cause a series of diseases. Shin et al. [26] found that the abundance of Proteobacteria in the intestines of healthy people was lower, while it increased significantly in diarrhea patients, and was accompanied by the increase of proinflammatory factor 
secretion. Durban et al. [27] also found that Proteobacteria may be involved in the occurrence of acute diarrhea. This is consistent with the results of the present study. DWT at $30{ }^{\circ} \mathrm{C}$ decreased the relative abundance of Proteobacteria in the cecum digesta of weaned piglets, accompanied by a reduced diarrhea rate and diarrhea index. Actinobacteria also plays an important role in maintaining animal health [28]. It has abilities to provide essential vitamins and amino acids, protecting the intestinal barrier, acidifying the intestinal microenvironment, inhibiting the growth of pathogenic bacteria and reducing the production of endotoxin. The present study suggested a decrease in the abundance of Actinobacteria in piglets provided with DWT at $30{ }^{\circ} \mathrm{C}$. It may be due to the complexity of the intestinal micro-ecosystem. Although the number of Actinobacteria went down, the abundance of other beneficial bacteria increased. Under their joint actions, the intestinal micro ecological balance was maintained and exhibited beneficial effects on growth performance.

Recent studies have found that Acidobacteria may be associated with the degradation of cellulose $[29,30]$, and Chloroflexi may be associated with the degradation of carbohydrates and amino acids [31]. In the present study, DWT at $13^{\circ} \mathrm{C}$ increased the abundance of Acidobacteria and Chloroflexi in the cecum digesta. One of the possible reasons is that feed is not fully digested in the small intestine, and the cecum digesta are still rich in nutrients, which is conducive to Chloroflexi survival.

Anaerovibrio is involved in lipid degradation, and its relative abundance grows as the dietary fat ratio increases [32]. Alloprevotella can produce short-chain volatile fatty acids, and its abundance in patients with metabolic syndrome and diabetes is significantly reduced [33,34]. In this study, DWT at $30^{\circ} \mathrm{C}$ improved the abundance of Anaerovibrio and Alloprevotella, which may increase the digestibility of crude fat.

Although piglets provided DWT at $30{ }^{\circ} \mathrm{C}$ had a low relative abundance of Lactobacilli than that of provided DWT at $13{ }^{\circ} \mathrm{C}$, DWT at $30{ }^{\circ} \mathrm{C}$ increased the relative abundance of Firmicutes and Bacteroidetes, and decreased the Proteobacteria abundance, compensating for the decrease in Lactobacilli. Under the joint action of these various microbes, a balanced intestinal micro-ecology was maintained.

\section{Conclusions}

Overall, the present data showed that the DWT should be set at $30^{\circ} \mathrm{C}$ and DWF at $300 \mathrm{~mL} / \mathrm{min}$ for weaned piglets in cold environments. This combination of DWT and DWF is beneficial for improving growth performance and feed efficiency, as well as decreasing diarrhea index in weaned pigs. These beneficial effects may be due to changes in microbial community compositions of the cecum, that led the weaned piglets to have higher utilization efficiency of energy, protein and fat in the feed. Therefore, the combination of drinking water parameters proposed in this study can be used to improve the body weight and health status of weaned piglets in future pig farm management during the cold season.

Author Contributions: Conceptualization, Z.Z. and Z.L.; data curation, H.Z., G.L., X.C., G.T. and J.C.; formal analysis, H.Z., G.L., X.C., G.T. and J.C.; funding acquisition, G.J.; investigation, Z.Z., H.Z.; methodology, Z.L.; software, Z.Z. and Z.L.; supervision, G.J.; validation, H.Z. and G.L.; Visualization, Z.Z. and Z.L.; writing_-original draft preparation, Z.Z. and Z.L.; writing — review and editing, G.J. All authors have read and agreed to the published version of the manuscript.

Funding: This work was supported by the National Key Research and Development Program of China (2017YFD0502000).

Conflicts of Interest: The authors declare no conflict of interest.

\section{References}

1. Lybrand, T.P.; Kollman, P.A. Water-water and water-ion potential functions including terms for many body effects. J. Chem. Phys. 1985, 83, 2923-2933. [CrossRef]

2. Yin, J.; Wu, M.M.; Xiao, H.; Ren, W.K.; Duan, J.L.; Yang, G.; Li, T.J.; Yin, Y.L. Development of an antioxidant system after early weaning in piglets. J. Anim. Sci. 2014, 92, 612-619. [CrossRef] [PubMed] 
3. Klose, V.; Bayer, K.; Bruckbeck, R.; Schatzmayr, G.; Loibner, A.P. In vitro antagonistic activities of animal intestinal strains against swine-associated pathogens. Vet. Microbiol. 2010, 144, 515-521. [CrossRef] [PubMed]

4. Tremaroli, V.; Backhed, F. Functional interactions between the gut microbiota and host metabolism. Nature 2012, 489, 242-249. [CrossRef] [PubMed]

5. Yang, H.; Huang, X.; Fang, S.; He, M.; Zhao, Y.; Wu, Z.; Yang, M.; Zhang, Z.; Chen, C.; Huang, L. Unraveling the Fecal Microbiota and Metagenomic Functional Capacity Associated with Feed Efficiency in Pigs. Front. Microbiol. 2017, 8, 1555. [CrossRef] [PubMed]

6. McCormack, U.M.; Curiao, T. Exploring a Possible Link between the Intestinal Microbiota and Feed Efficiency in Pigs. Appl. Environ. Microbiol. 2017, 83. [CrossRef]

7. Committee on Nutrient Requirements of Swine, National Research Council. Nutrient Requirements of Swine, 11th ed.; National Academy Press: Washington, DC, USA, 2012.

8. Marquardt, R.R.; Jin, L.Z.; Kim, J.W.; Fang, L.; Frohlich, A.A.; Baidoo, S.K. Passive protective effect of egg-yolk antibodies against enterotoxigenic Escherichia coli K88+ infection in neonatal and early-weaned piglets. FEMS Immunol. Med. Microbiol. 1999, 23, 283-288. [CrossRef]

9. Mao, X.; Hu, H.; Xiao, X.; Chen, D.; Yu, B.; He, J.; Yu, J.; Zheng, P.; Luo, J.; Luo, Y.; et al. Lentinan administration relieves gut barrier dysfunction induced by rotavirus in a weaned piglet model. Food Funct. 2019, 10, 2094-2101. [CrossRef] [PubMed]

10. Vogtmann, H.; Pfirter, H.P.; Prabucki, A.L. A new method of determining metabolisability of energy and digestibility of fatty acids in broiler diets. Br. Poult. Sci. 1975, 16, 531-534. [CrossRef]

11. AOAC International. Official Methods of Analysis of the Association of Official Analytical Chemists, 18th ed.; AOAC International: Gaitherburg, MD, USA, 2007; pp. 11-23.

12. Bovera, F.; Lestingi, A.; Iannaccone, F.; Tateo, A.; Nizza, A. Use of dietary mannanoligosaccharides during rabbit fattening period: Effects on growth performance, feed nutrient digestibility, carcass traits, and meat quality. J. Anim. Sci. 2012, 90, 3858-3866. [CrossRef] [PubMed]

13. Caporaso, J.G.; Kuczynski, J.; Stombaugh, J.; Bittinger, K.; Bushman, F.D.; Costello, E.K.; Fierer, N.; Pena, A.G.; Goodrich, J.K.; Gordon, J.I.; et al. QIIME allows analysis of high-throughput community sequencing data. Nat. Methods 2010, 7, 335-336. [CrossRef] [PubMed]

14. DeSantis, T.Z.; Hugenholtz, P.; Larsen, N.; Rojas, M.; Brodie, E.L.; Keller, K.; Huber, T.; Dalevi, D.; Hu, P.; Andersen, G.L. Greengenes, a chimera-checked $16 \mathrm{~S}$ rRNA gene database and workbench compatible with ARB. Appl. Environ. Microbiol. 2006, 72, 5069-5072. [CrossRef] [PubMed]

15. Bokulich, N.A.; Subramanian, S.; Faith, J.J.; Gevers, D.; Gordon, J.I.; Knight, R.; Mills, D.A.; Caporaso, J.G. Quality-filtering vastly improves diversity estimates from Illumina amplicon sequencing. Nat. Methods 2013. [CrossRef] [PubMed]

16. Nienaber, J.A.; Hahn, G.L. Effects of water flow restriction and environmental factors on performance of nursery-age pigs. J. Anim. Sci. 1984, 59, 1423-1429. [CrossRef]

17. Leibbrandt, V.D.; Johnston, L.J.; Shurson, G.C.; Crenshaw, J.D.; Libal, G.W.; Arthur, R.D. Effect of nipple drinker water flow rate and season on performance of lactating swine. J. Anim. Sci. 2001, 79, 2770-2775. [CrossRef] [PubMed]

18. Browning, K.N.; Travagli, R.A. Central nervous system control of gastrointestinal motility and secretion and modulation of gastrointestinal functions. Compr. Physiol. 2014, 4, 1339-1368.

19. Jimenez, C.; Regnard, J.; Robinet, C.; Mourot, L.; Gomez-Merino, D.; Chennaoui, M.; Jammes, Y.; Dumoulin, G.; Desruelle, A.V.; Melin, B. Whole body immersion and hydromineral homeostasis: Effect of water temperature. Eur. J. Appl. Physiol. 2010, 108, 49-58. [CrossRef]

20. Kim, H.B.; Borewicz, K.; White, B.A.; Singer, R.S.; Sreevatsan, S.; Tu, Z.J.; Isaacson, R.E. Longitudinal investigation of the age-related bacterial diversity in the feces of commercial pigs. Vet. Microbiol. 2011, 153, 124-133. [CrossRef]

21. Eckburg, P.B.; Bik, E.M.; Bernstein, C.N.; Purdom, E.; Dethlefsen, L.; Sargent, M.; Gill, S.R.; Nelson, K.E.; Relman, D.A. Diversity of the human intestinal microbial flora. Science 2005, 308, 1635-1638. [CrossRef]

22. Backhed, F.; Ley, R.E.; Sonnenburg, J.L.; Peterson, D.A.; Gordon, J.I. Host-bacterial mutualism in the human intestine. Science 2005, 307, 1915-1920. [CrossRef]

23. Salyers, A.A. Bacteroides of the human lower intestinal tract. Annu. Rev. Microbiol. 1984, 38, $293-313$. [CrossRef] [PubMed] 
24. Grover, M. Role of gut pathogens in development of irritable bowel syndrome. Indian. J. Med. Res. 2014, 139, 11-18. [PubMed]

25. Mukhopadhya, I.; Hansen, R.; El-Omar, E.M.; Hold, G.L. IBD-what role do Proteobacteria play? Nat. Rev. Gastroenterol. Hepatol. 2012, 9, 219-230. [CrossRef] [PubMed]

26. Shin, N.R.; Whon, T.W.; Bae, J.W. Proteobacteria: Microbial signature of dysbiosis in gut microbiota. Trends. Biotechnol. 2015, 33, 496-503. [CrossRef]

27. Durban, A.; Abellan, J.J.; Jimenez-Hernandez, N.; Artacho, A.; Garrigues, V.; Ortiz, V.; Ponce, J.; Latorre, A.; Moya, A. Instability of the faecal microbiota in diarrhoea-predominant irritable bowel syndrome. FEMS Microbiol. Ecol. 2013, 86, 581-589. [CrossRef] [PubMed]

28. Kothe, E. Special Focus: Actinobacteria. J. Basic. Microbiol. 2018, 58. [CrossRef] [PubMed]

29. Pankratov, T.A.; Kirsanova, L.A.; Kaparullina, E.N.; Kevbrin, V.V.; Dedysh, S.N. Telmatobacter bradus gen. nov., sp. nov., a cellulolytic facultative anaerobe from subdivision 1 of the Acidobacteria, and emended description of Acidobacterium capsulatum Kishimoto et al. 1991. Int. J. Syst. Evol. Microbiol. 2012, 62, 430-437. [CrossRef] [PubMed]

30. Eichorst, S.A.; Kuske, C.R.; Schmidt, T.M. Influence of plant polymers on the distribution and cultivation of bacteria in the phylum Acidobacteria. Appl. Environ. Microbiol. 2011, 77, 586-596. [CrossRef]

31. Yamada, T.; Sekiguchi, Y.; Imachi, H.; Kamagata, Y.; Ohashi, A.; Harada, H. Diversity, localization, and physiological properties of filamentous microbes belonging to Chloroflexi subphylum I in mesophilic and thermophilic methanogenic sludge granules. Appl. Environ. Microbiol. 2005, 71, 7493-7503. [CrossRef] [PubMed]

32. Huws, S.A.; Lee, M.R.; Muetzel, S.M.; Scott, M.B.; Wallace, R.J.; Scollan, N.D. Forage type and fish oil cause shifts in rumen bacterial diversity. FEMS Microbiol. Ecol. 2010, 73, 396-407. [CrossRef] [PubMed]

33. Zhang, X.; Zhao, Y.; Xu, J.; Xue, Z.; Zhang, M.; Pang, X.; Zhang, X.; Zhao, L. Modulation of gut microbiota by berberine and metformin during the treatment of high-fat diet-induced obesity in rats. Sci. Rep. 2015, 5. [CrossRef] [PubMed]

34. Schwiertz, A.; Taras, D.; Schafer, K.; Beijer, S.; Bos, N.A.; Donus, C.; Hardt, P.D. Microbiota and SCFA in lean and overweight healthy subjects. Obesity (Silver Spring) 2010, 18, 190-195. [CrossRef] [PubMed]

(C) 2020 by the authors. Licensee MDPI, Basel, Switzerland. This article is an open access article distributed under the terms and conditions of the Creative Commons Attribution (CC BY) license (http://creativecommons.org/licenses/by/4.0/). 